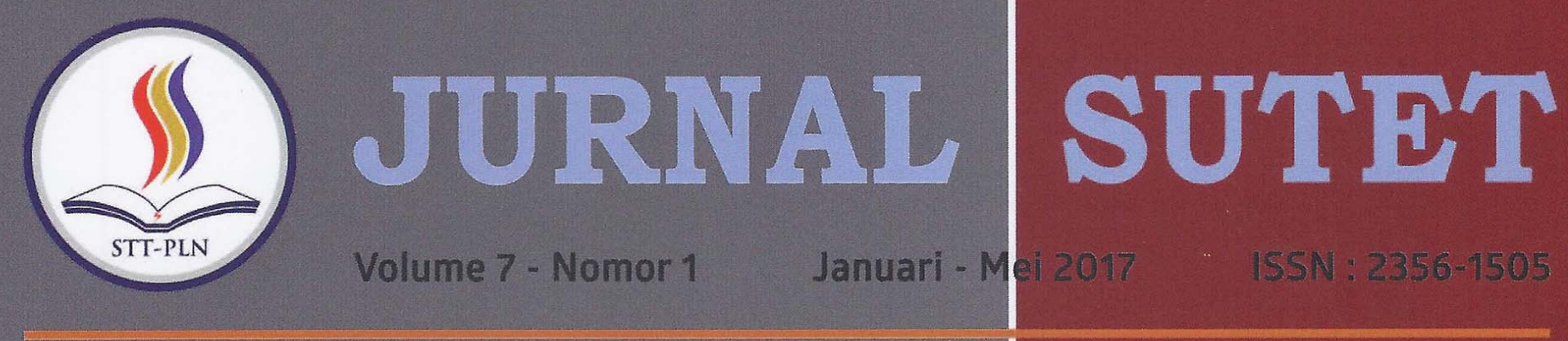

DESAIN SISTEM ALARM MOBIL BERBASIS SMS

Erlina; Hendrianto Husada; Bambang Tri Atmodjo

KELAYAKAN PENGGUNAAN PENDINGIN THERMOELEKTRIK UNTUK PENGHEMATAN DAYA LISTRIK PADA BASE TRANSCEIVER

Sunaryo; Uno Bintang Sudibyo; Supriadi Legino

WITRICITY (WIRELESS ELECTRICITY)

Aas Wasri Hasanah; Oktaria Handayani

CONCEPTUAL DESIGN FOR MITIGATING HARMONIC DISTORTION ON ESP INSTALLATION: CASE STUDY IN KAJI SEMOGA FIELD, MEDCO E\&P INDONESIA

Sandy Suryakusuma; Suprapto Atmowiranto; Dadang Darmawan

RANCANGAN RANGKAIAN ANTI BOUNCING UNTUK RANGKAIAN DIGITAL

Tasdik Darmana

STUDI POWER WHEELING DIKAWASAN INDUSTRI JABABEKA

Bimo Brillianta; Uno Bintang Sudibyo; Wildan Aripin

PEMASANGAN ARRESTER DAN ARCING HORN PADA PENGHANTAR BERISOLASI DI SUTM $20 \mathrm{kV}$ Christine Widyastuti; Andi Makkulau

PENGELOLAAN EMISI GAS LANDFILL (BIOGAS) SEBAGAI ENERGI TERBARUKAN Isworo Pujotomo; Muchamad Nur Qosim

DISAIN SISTEM PENTANAHAN PROTEKSI PETIR SISTEM MULTIPLE VERTICAL ELECTRODES PADA TERMINAL LAWE-LAWE - PERTAMINA DHP

Ibnu Hajar

ANALISA DCS (DISTRIBUTED CONTROL SYSTEM) PADA PROSES POLIMERISASI

Syarif Hidayat; Irsyadi Akbar Jay

PENGEMBANGAN TEKNOLOGI SISTEM SMART MICROGRID DI SEKOLAH TINGGI TEKNIK PLN Heri Suyanto; Agung Hariyanto

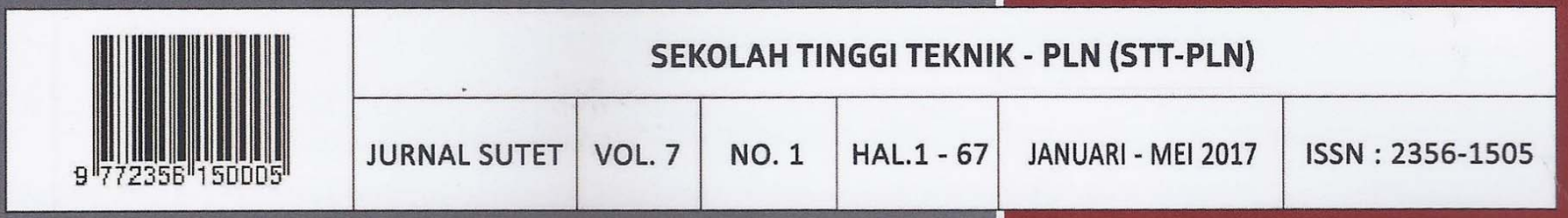




\title{
DESAIN SISTEM ALARM MOBIL BERBASIS SMS
}

\author{
Erlina $^{1)}$, Hendrianto Husada ${ }^{2)}$, Bambang Tri Atmodjo ${ }^{3)}$ \\ Teknik Elektro, Sekolah Tinggi Teknik PLN \\ 1erlina@sttpln.ac.id \\ ²hendrianto_h@yahoo.com
}

\begin{abstract}
The alarm device is very important in a vehicle, especially on four-wheeled vehicles. Alarm device installed to avoid in case of danger of theft or destruction of the car. So designed car alarm system that can send short message to car owner who use AT89S52 microcontroller. The hardware arrangement of the car alarm system uses the SMS-based AT89S52 microcontroller in this design, consisting of four main parts of the circuit, the minimum system circuit of microcontroller, power supply, serial communication, Input / Output. In SMS text sent from Wavecom M1306B modem and received by mobile (mobile phone) to SMS center or SMS Center flows in form of PDU (Protocol Data Unit). In the sms format is divided into several segments of data that each segment has a specific purpose. The segments are: SMS center number, destination number, bytes for the purpose of setting this SMS and most important is the SMS content that has been changed in the form of a PDU. To be able to send or upload SMS data to the modem and ordered the modem to send SMS data it required AT Command instructions.
\end{abstract}

Keywords: Alarm, SMS (short masage system), Modem, Cellular Phone.

Abstrak : Perangkat alarm sangatlah penting dalam suatu kendaraan terutama pada kendaraan roda empat. Perangkat alarm dipasang untuk menghindari bila terjadi adanya bahaya pencurian atau pengrusakan pada mobil. Maka dirancanglah sistem alarm mobil yang dapat mengirim pesan singkat kepada pemilik mobil yang menggunakan mikrokontroler AT89S52. Susunan perangkat keras sistem alarm mobil menggunakan mikrokontroler AT89S52 yang berbasis SMS pada perancangan ini, terdiri atas empat bagian utama rangkaian, yaitu rangkaian sistem minimum mikrokontroler, catu daya, komunikasi serial, Input/Output. Pada teks SMS yang dikirim dari modem Wavecom M1306B dan diterima oleh ponsel (telepon seluler) menuju pusat SMS atau SMS Center mengalir dalam bentuk PDU (Protocol Data Unit). Pada format sms dibagi menjadi beberapa segmen data yang setiap segmen itu mempunyai maksud yang spesifik. Segmen- segmen itu adalah : nomor SMS center, nomor tujuan, byte-byte untuk keperluan setting SMS ini dan yang terpenting adalah isi SMS itu yang telah diubah dalam bentuk PDU. Untuk dapat mengirimkan atau upload data SMS ke modem dan memerintahkan modem untuk mengirimkan data SMS itu diperlukan instruksi AT Command.

Kata kunci : Alarm, SMS (short masage system), Modem, Telepon Selular.

\section{PENDAHULUAN}

Dewasa ini pencurian mobil semakin merajalela sehingga banyak dijumpai alatalat pengaman yang canggih. Semakin maraknya kejahatan pencurian mobil menuntut pemilik mobil untuk lebih berhati-hati dan memiliki sistem keamanan ekstra selain kunci utama saat mobil diparkir atau ditinggal oleh pemiliknya. Hilangnya barang-barang berharga tersebut mengakibatkan kerugian yang tidak sedikit. Untuk mengantisipasi hal tersebut salah satu alat keamanan mobil saat diparkir atau ditinggal oleh pemiliknya adalah berupa alarm. Kebanyakan alarm-alarm yang ada di pasaran saat ini adalah alarm yang berupa suara atau konvensional, yaitu alarm yang berbunyi di saat switch pemicu 
terhubung atau sensor pada alarm mendapat respon sehingga alarm berbunyi. Tapi sering kali terjadi pemilik mobil tidak mendengar bunyi alarm mobilnya karena jarak yang jauh antara tempat parkir mobil dengan tempat aktifitas pemilik mobil.

Dengan maraknya penggunaan ponsel untuk berkirim SMS, maka kemudian muncul untuk membuat layanan berbasis SMS. Pada teks SMS yang dikirim dari ponsel (telepon seluler) menuju pusat SMS atau SMS Center mengalir dalam bentuk PDU (Protocol Data Unit). Begitu juga pesan SMS yang diterima oleh ponsel dari pusat SMS (SMS Center) disimpan didalam ponsel berbentuk PDU Pesan-pesan SMS dalam bentuk PDU yang terdapat didalam ponsel tersebut dapat dibaca oleh perangkat lain (komputer) melalui gerbang keluaran/ masukan yang terdapat pada ponsel secara serial. PDU tersusun dari beberapa bagian kepala atau header yang menyimpan informasi berupa bilanganbilangan heksa desimal. Adapun tujuan penelitian adalah mengembangkan sistem alarm mobil yang akan membantu pemilik kendaraan agar lebih aman dalam menjaga keamanan kendaraannya.

\section{TEORI PENUNJANG}

\subsection{Sensor}

Pada perancangan sistem alarm ini sensor yang digunakan adalah sensor switch. Sensor ini dipasang pada titik-titik tertentu pada mobil seperti pada pintu mobil, bagasi dan kap mesin. Pada dasarnya switch bisa diaplikasikan untuk sensor mekanik, karena alat ini bisa dipakai pada mikrokontroler untuk pengaturan rangkaian pengontrolan.

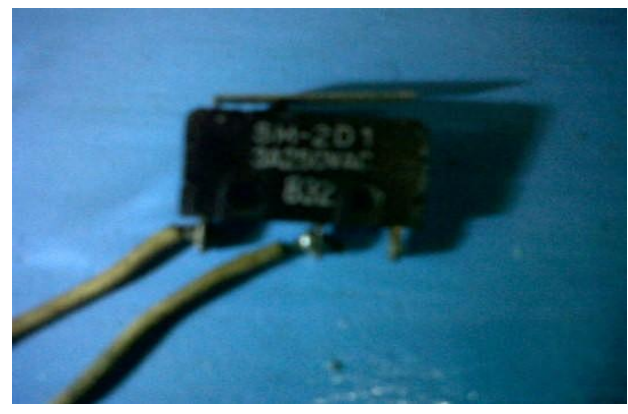

Gambar 1. Switch

\subsection{Indikator}

Untuk indikator yang digunakan adalah LED (Light Emitting Dioda) dan buzzer. Pada dasarnya LED adalah sejenis dioda semikonduktor istimewa dengan berbagai macam warna. Seperti sebuah dioda normal, LED terdiri dari sebuah chip bahan semikonduktor yang diisi penuh atau di-dop. Dengan ketidakmurnian untuk menciptakan sebuah struktur yang disebut $p$-n junction. Pembawa muatan elektron dan lubang elektron mengalir ke junction dari elektroda dengan tegangan berbeda. Ketika elektron bertemu dengan lubang, elektron jatuh ke tingkat energi yang lebih rendah, dan melepas energi dalam bentuk photon.

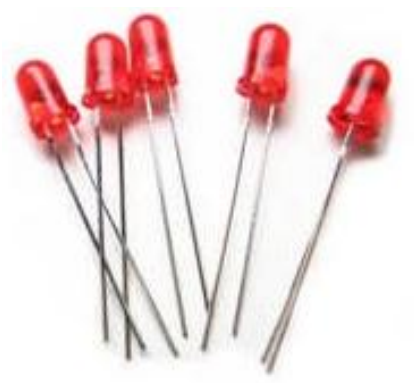

Gambar 2. LED

Sedangkan pengertian dasar dari buzzer adalah alat penderu (sirine) yang menggunakan sumber arus listrik untuk menghasilkan bunyi menderu terus menerus. Dengan mikrokontroler, kita dapat mengatur tempo suara buzzer yang monotone dengan bermacam-macam tempo.

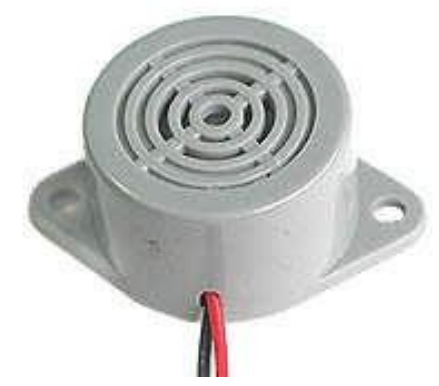

Gambar 3. Buzzer

\subsection{Catu Daya}

Catu daya berfungsi untuk mensupply tegangan yang telah dirubah ke komponen mikrokontroler, catu daya diaplikasikan sebagai accu atau baterai pada mobil. 

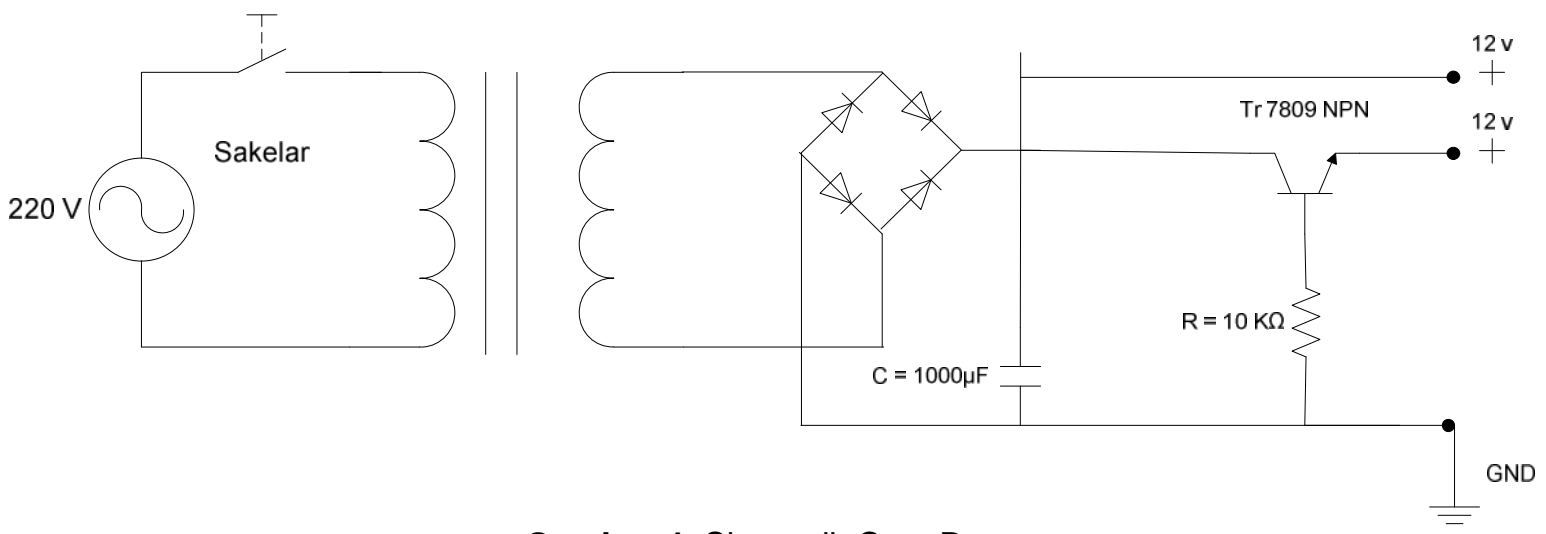

Gambar 4. Skematik Catu Daya

\subsection{Mikrokontroler}

Mikrokontroler adalah salah satu dari bagian dasar suatu sistem komputer. Meskipun mempunyai bentuk yang jauh lebih kecil dari suatu komputer pribadi, mikrokontroler dibangun dari elemenelemen dasar yang sama. Seperti umumnya komputer, mikrokontroler adalah alat yang mengerjakan instruksiinstruksi yang diberikan kepadanya. Artinya, bagian terpenting dan utama dari suatu sistem terkomputerisasi adalah program itu sendiri yang dibuat oleh seorang programmer. Program ini menginstruksikan komputer untuk melakukan jalinan yang panjang dari aksiaksi sederhana untuk melakukan tugas yang lebih kompleks yang diinginkan oleh programmer. Dengan mikrokontroler maka sistem elektronik akan menjadi lebih ringkas, rancang bangun sistem elektronik akan lebih cepat karena sebagian besar dari sistem adalah perangkat lunak yang mudah untuk dimodofikasi dan pencarian gangguan lebih mudah untuk ditelusuri karena sistemnya yang kompak.

Mikrokontroler berfungsi juga sebagai alat pengontrol dan menghasilkan output logic yang digunakan untuk mendrive relay sehingga alat yang dikontrol tidak hanya yang berlevel TTL tetapi juga alatalat yang menggunakan AC (Alternative Current) seperti lampu bohlam, kipas angin, dan radio.

\subsection{Spesifikasi Modem Wavecom M1306B}

Modem GPRS Wavecom Fastrack M1306B (Chipset Q2406B module) USB, modem ini mendukung $A T$ command dan dapat digunakan oleh seluruh aplikasi SMS berbasis AT Command. Modem ini dapat juga digunakan untuk PPOB, GPRS data.

Isi dalam satu paket modem M1306B (Q2403B) USB yaitu : Modem, Kabel USB, Kabel Serial RS232, Antenna.

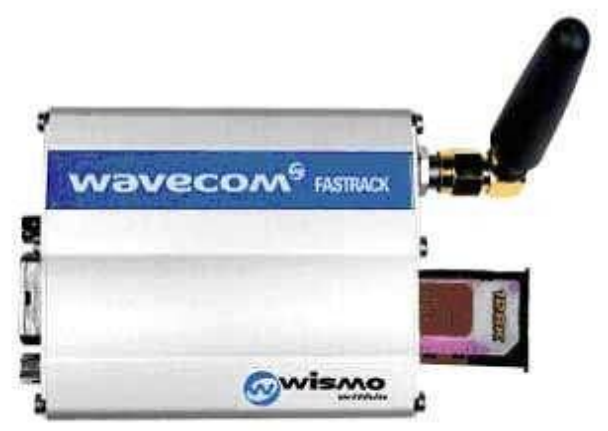

Gambar 5. Modem Wavecom M1306B

\subsection{IC RS 232}

Istilah RS232 sudah begitu populer sehingga sering dianggap RS232 mengatur semua hal tentang komunikasi data seri, meskipun sesungguhnya RS232 tidak mengatur sejauh itu. Pemahaman spesifikasi RS232 bisa sangat membantu menghubungkan alat berbasis mikrokontroler dengan Modem standard.

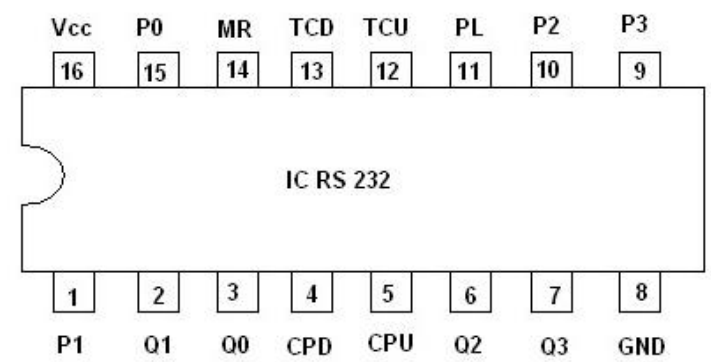

Gambar 6. IC TTL RS 232 


\section{METODE PENELITIAN}

\subsection{PERANCANGAN ALAT}

Alarm mobil berbasis SMS merupakan sistem keamanan pada kendaraan yang telah berkembang seiring kemajuan zaman. Sistem alarm ini dilengkapi dengan mikrokontroler dan modem Wavecom M1306B yang

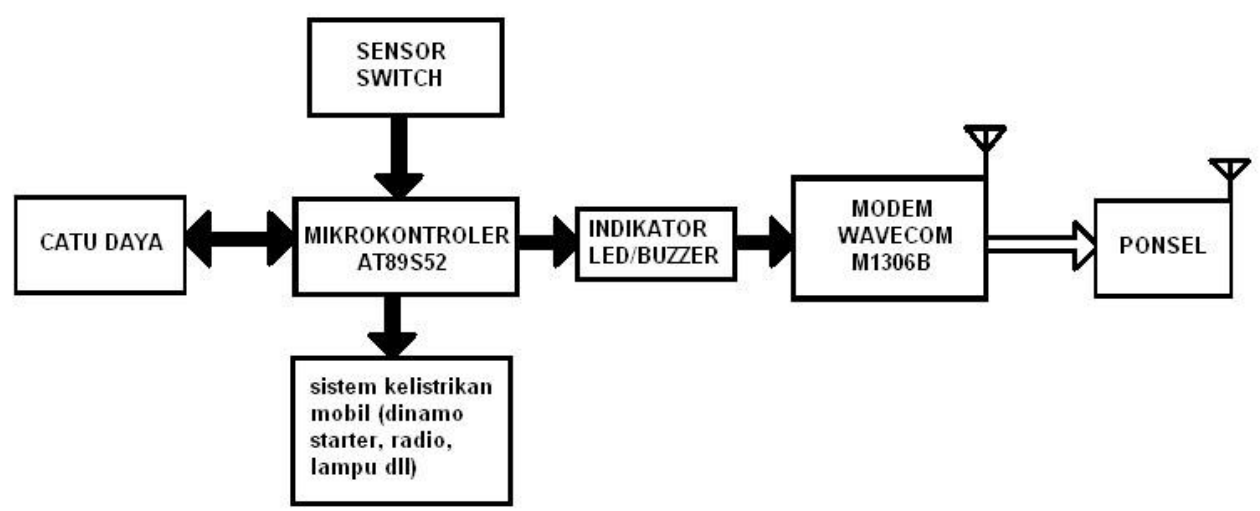

Gambar 7. Blok Diagram Sistem Alarm Mobil Berbasis SMS dirancang sedemikian rupa sehingga ketika sistem alarm aktif karena adanya gangguan maka mikrokontroler akan memerintah modem Wavecom M1306B pada mobil untuk mengirim pesan singkat kepada pemilik kendaraan.

\subsection{Flow Chart Sistem Alarm Mobil Berbasis SMS}

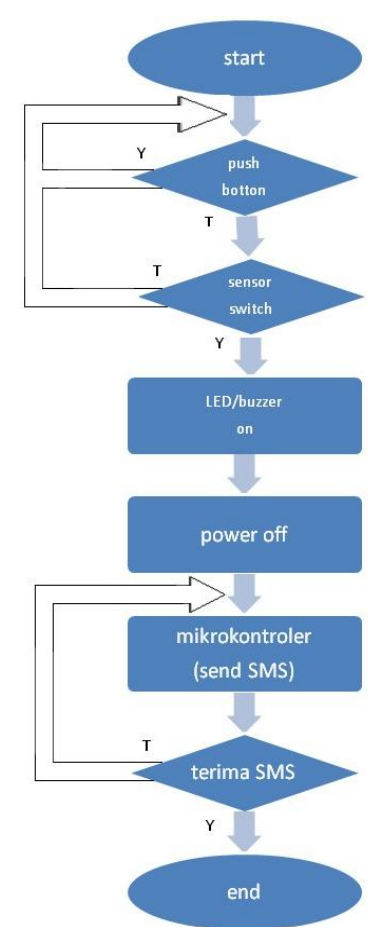

\section{HASIL DAN PEMBAHASAN}

Alarm mobil berbasis SMS adalah sistem keamanan pada kendaraan yang dapat mengirimkan pesan kepada pemilik mobil pada saat alarm kendaraan dalam keadaan aktif. Setelah perancangan aplikasi selesai, perlu dilakukan pengujian untuk mengetahui cara kerja alat dan menganalisa tingkat keakuratan, keunggulan, kelemahan, dan keterbatasan spesifikasi dari aplikasi yang telah dibuat.

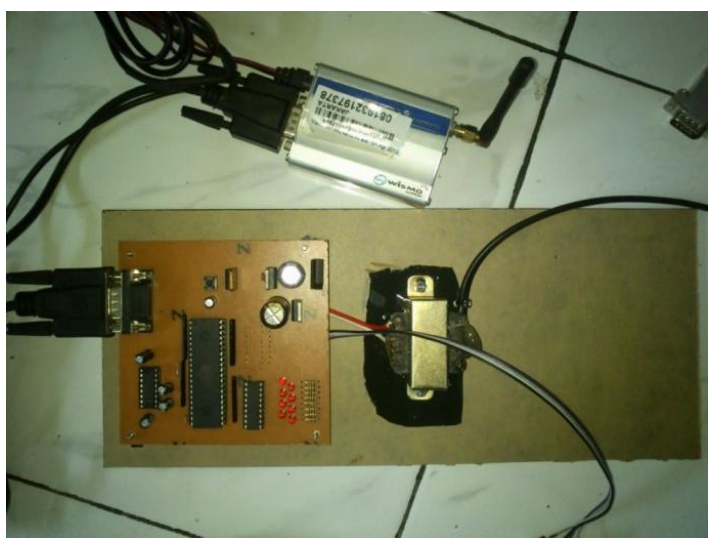

Gambar 8. Rangkaian Alarm Mobil Berbasis SMS

Pengujian yang akan dilakukan dibagi menjadi dua tahapan, tahapan-tahapan tersebut adalah :

1. Pengujian terhadap titik yang dipasang switch sebagai sensor untuk mentriger sistem alarm. 
2. Analisa pengiriman SMS oleh modem Wavecom M1306B ketika alarm aktif.

3. Analisa program bahasa assembly pada mikrokontroler AT89S52 menggunakan perintah ATCommand, untuk sistem alarm mobil berbasis SMS.

\subsection{Pengujian Terhadap Sensor Switch}

Pada dasarnya sensor yang digunakan pada mobil adalah sensor break glass yaitu sensor getar (sensor yang bisa mendeteksi getaran/guncangan) atau sensor gerak yang bisa mendeteksi posisi suatu benda (diletakkan disuatu tempat pada mobil dan dirancang sedemikian rupa agar bisa mendeteksi pergerakan atau perubahan posisi mobil saat parkir). Untuk aplikasi ini sensor yang digunakan adalah sensor switch, yang diletakan pada titik tertentu seperti pintu mobil, bagasi dan kap mesin.

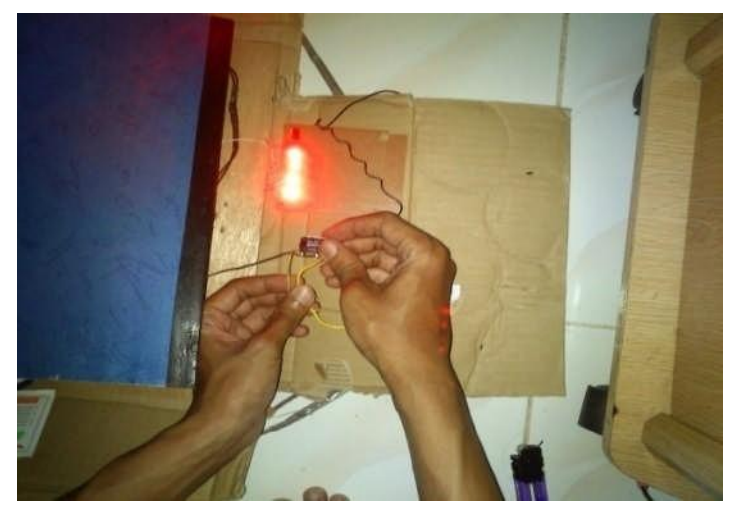

Gambar 9. Pengujian Sensor Switch

Tabel 1. Pengujian Sensor Switch

\begin{tabular}{|l|l|l|}
\hline Sensor & LED & Buzzer \\
\hline Switch 1 on & Hidup & Hidup \\
\hline Switch 2 on & Hidup & Hidup \\
\hline Switch 3 on & Hidup & Hidup \\
\hline Switch 4 on & Hidup & Hidup \\
\hline
\end{tabular}

\subsection{Analisa Cara Kerja Sistem Alarm Mobil Berbasis SMS}

Pada mikrokontroler telah disetting format isi SMS yang akan dikirim pada saat alarm hidup. Bahasa pemrograman yang dipakai untuk mikrokontroler adalah bahasa assembly, bahasa assembly digunakan agar lebih mudah dibaca oleh modem Wavecom M1306B dalam mengolah data atau yang lebih dikenal dengan text support mode/ PDU support mode.

Ketika alarm hidup mikrokontroler akan memberikan perintah kepada modem Wavecom M1306B untuk mengirim pesan ke nomor-nomor ponsel yang telah didaftarkan. Pengiriman SMS dengan modem menggunakan frekuensi sinyal GSM, sama dengan pengiriman SMS dari ponsel ke ponsel seperti biasanya. Jadi jarak jangkauan pengirim dan penerima bisa sejauh mungkin selagi sinyal GSM dapat menjangkaunya atau suatu hal yang dapat menybabkan sinyal hilang seperti habisnya masa berlaku SIM card pada modem.

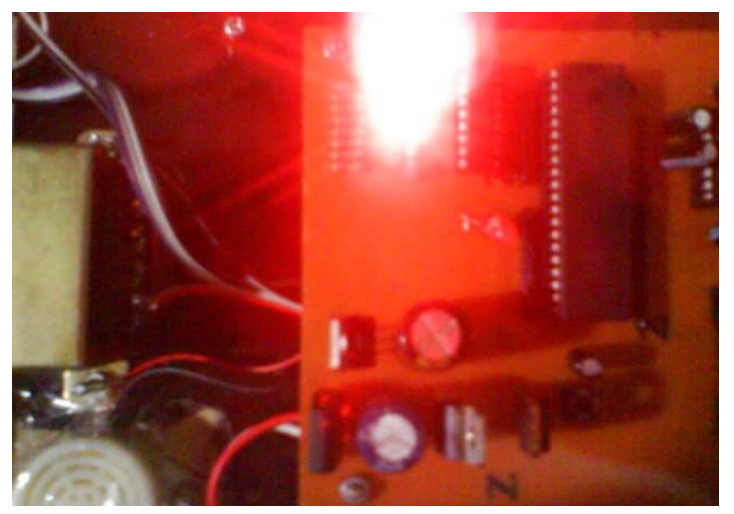

Gambar 10. Sistem Alarm Dalam Keadaan Siaga (Standby)

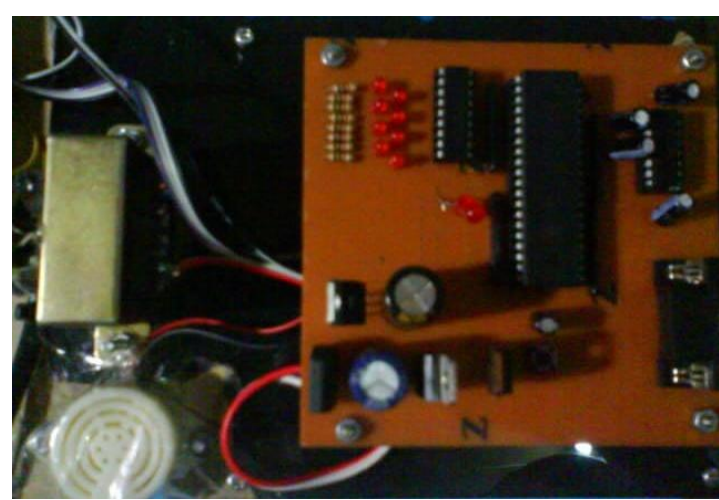

Gambar 11. Sistem Kelistrikan Mati Ketika Switch Trigger 


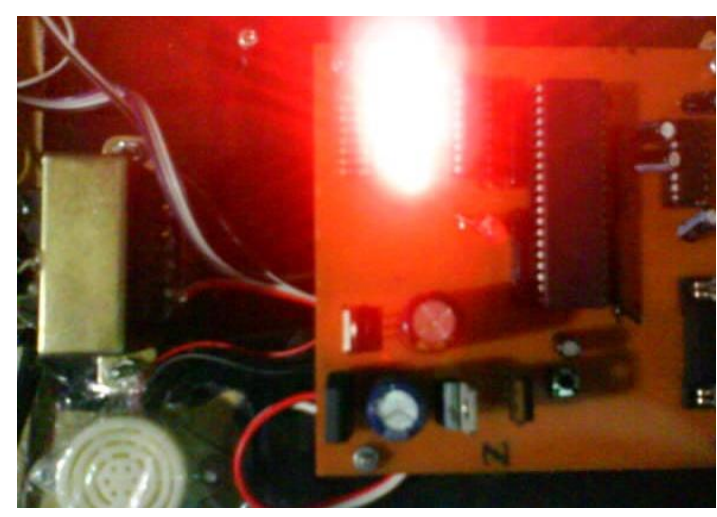

Gambar 12. Alarm On LED dan Buzzer Hidup

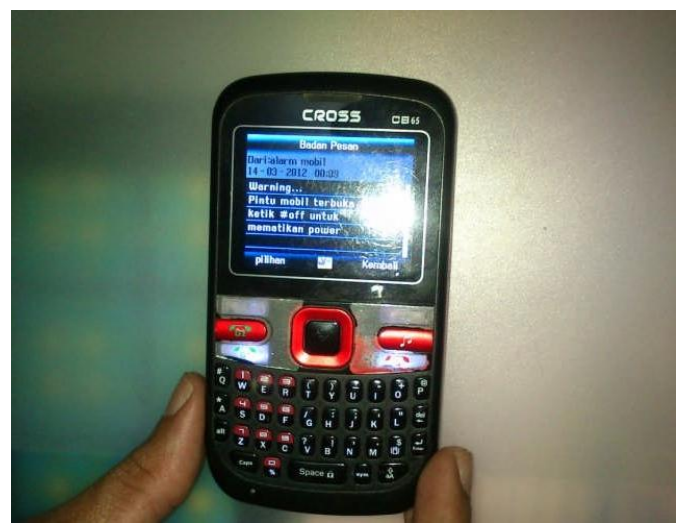

Gambar 13. Pesan Diterima Ketika Alarm Hidup

Dari analisa kerja alat ini, yaitu dari gambar 10 sampai 13 membuktikan ketika sistem alarm dalam keadaan siaga lalu berubah menjadi keadaan aktif/on, maka dengan otomatis indikator berupa LED dan buzzer hidup serta sistem kelistrikan pada mobil mati, sehingga starter pada mobil tidak aktif. Pada perancangan ini disetting pada rangkaian kabel menuju busi mobil juga terputus secara otomatis bersamaan ketika sistem kelistrikan mati, sehingga dengan cara apapun mobil tidak bisa hidup. Sistem mikrokontroler akan mengirim SMS kepada pemilik mobil, dalam hal ini SMS hanya pemberitahuan jika mobil dalam keadaan tidak aman. Maka pemilik mobil harus mendatangi dan memeriksa keadaan mobilnya setelah SMS diterima. Serta untuk mereset kembali sistem alarm dalam keadaan siaga/standby.
Tabel 2. Nomor Ponsel Yang MenerimaSMS Dari Alarm Mobil

\begin{tabular}{|l|l|l|}
\hline Nomor Ponsel & Report & $\begin{array}{l}\text { Jeda } \\
\text { waktu }\end{array}$ \\
\hline 08131517 xxxx & Berhasil & 5 detik \\
\hline 08131572 xxxx & Berhasil & 5 detik \\
\hline 08180973 xxxx & Berhasil & 5 detik \\
\hline 0812814 xxxx & Berhasil & 5 detik \\
\hline
\end{tabular}

\section{KESIMPULAN}

Berdasarkan hasil pengujian dan analisa alat sistem alarm menggunakan mikrokontroler AT89S52 berbasis SMS ini, maka dapat diambil beberapa kesimpulan yaitu:

1. Sistem alarm akan mengirim pesan singkat atau SMS ketika sensor switch aktif/on disertai hidupnya indikator berupa LED dan buzzer.

2. Alarm tidak dapat dimatikan dari jarak jauh, hal ini dilakukan agar pemilik mobil harus mendatangi dan memeriksa keadaan mobilnya yang sedang dalam keadaan tidak aman sekaligus mereset sistem alarm agar kembali pada keadaan siaga/standby.

3. Sistem secara otomatis memutus tegangan ke dinamo starter ketika alarm hidup, sehingga mobil tidak bisa dihidupkan dengan cara apapun, tetapi alarm tetap dalam keadaan hidup/bunyi.

4. Pengiriman atau penerimaan SMS akan berjalan dengan baik jika kondisi sinyal GSM pada keadaan stabil/normal.

\section{REFERENSI}

Anonim. 2012. Pemrograman Bahasa Assembly.

http://www.scribd.com/mas_affandy/pemro graman-bahasa-assembly. Diakses 2 Maret 2012.

Anonim. 2012. Rangkaian Sistem Minimum Mikrokontroler AT89S51/52.

http://tutorial-elektronika.blogspot.com /2009/02/rangkaian-sistem- 
minimummikrokontroler.html. Diakses 15 Februari 2012.

Anonim. 2012. Wavecom M1306B. http://onlinestore.astel.asia. Diakses 13 Maret 2012.

Erlina. 2008. "Diktat Sensor \& Transducer". STT-PLN Jakarta.

Darmana, Tasdik. 2009. "IC TTL dan Data Sheet, Diktat Perancangan Sistem Digital". STT-PLN Jakarta.

Joko, Tri. 2011. "Diktat Sensor Mekanik". STT-PLN Jakarta.

Marwita, Fifit. 2008. "Diktat Komputer \& Pemrograman". STT-PLN Jakarta.

Putra, Agfianto Eko. 2003. "Belajar Mikrokontroler". Teori dan aplikasi, edisi ke-2. Penerbit Gava Media. Yogyakarta.

Sumisjokartono. 1985. "Elektronika Praktis". Penerbit PT. Elex Media Komputindo. Jakarta.

Sugiharto, Agus. 2002. "Penerapan Dasar Transducer dan Sensor". Penerbit Kanisius. Indonesia.

Untoro, Agung. 2007. "Diktat Sistem Mikroprosesor dan Mikrokontroler". STT-PLN Jakarta. 